\title{
Civil Society Organisations in Research: A Literature-based Typology
}

\begin{abstract}
This article explores literatures from various sources to highlight and understand differences among key players surrounding the perceived nature and role of civil society in research from different literature streams. Including civil society organisations (CSOs) in research activities is an integral part of a broad drive towards integration of science and society. Interest in CSO inclusion in research is widespread, but lacks a coherent focus and clarity on what CSOs are. Without this clarity, CSO-inclusive research, or policy, may be ineffective. This article addresses this gap in knowledge by presenting findings from an exploration of academic, policy and research project literature in order to come to a view on CSOs in research. This culminates in a typology of CSOs and provides a means of identifying types of CSOs. The typology shows four main types of CSO (Common cause, Shared voice, Research-oriented, Commercially-oriented) and provides a definition for each type, along with a basis for the definition; an example of each; some typical terminology; typical area of activity; properties; typical mission; key areas of interest and their 'action logic' in research.
\end{abstract}

Key words

Civil Society Organisations, Research, Policy, Literature Review, Typology 


\section{Introduction}

There is a general trend in research policy and practice toward broader stakeholder engagement in technical and scientific projects. Civil Society Organisations (CSOs) are critically discussed as important actors who can realise the promise of participative research, responsive to the real world (Smismans, 2008). CSOs are looked upon favourably by both policymakers (European Commission, 2011a, p. 9) and individuals (Bernauer \& Gampfer, 2013a, p. 448) as players in policymaking . They are seen as alliance-brokers between public and policymakers (Mercer \& Green, 2013, p. 107; Scholz, 2005, p. 682). This ability to participate in agenda-setting at a policy level is reflected in the ambition that CSOs' expertise be included at research project-level agenda-setting (European Science Foundation, 2013, p. 18; É. Gall, Neubauer, Millot, \& Piasecki, 2011, p. 47). Traditionally, CSO partners fulfil a dissemination role (Revel, Spruyt, \& Soubiran, 2012, p. 18) which can be attributed to their acknowledged excellence in communicating science to the public and societal groups (European Commission, 2012, p. 62; Mercer \& Green, 2013, p. 108). Another aspect of this communicative excellence is the sectoral knowledge and oversight CSOs can provide in research (Bernauer \& Gampfer, 2013, pp. 440, 441; Gómez-Jauregui, 2004, p. 43). Essentially, much of these abilities are rooted in the trust that CSOs can engender for the aims and practices of research projects (Tsipouri, 2012a, p. 733) and the perceived legitimacy of research project outputs.

Moreover, as scientific research often claims to provide societal benefits, or to generate social goods, its evaluation would seem to require a component with insight into facets of 'the social', broadly understood. A standard, expert, peer evaluation of scientific research cannot necessarily justify a claim to be well-positioned or informed enough to assess researchers' claims about social goods emanating from scientific research. Perhaps not least as a consequence of this 
perceived gap, there are numerous attempts to stimulate participation in research and embed participative processes in research governance (Dröll, 2014).

There is, however, no straightforward approach to understanding CSO roles (Steen-Johnsen, Eynaud, \& Wijkström, 2011) nor consensus on the definition of CSOs in research. Between CSOs, non-governmental organisations (NGOs), charities, business advocacy organisations and other types of organisation, it is not immediately clear if and how they resolve into distinct and mutually exclusive groups. It is unclear what typical behaviours and interests they may manifest, and what effect this might have on research or research policy (TACSO, 2010; Tomlinson, 2013, Annex 1). This conceptualisation challenge extends far beyond the limits of research only, as is developed clearly in (Salamon \& Sokolowski, 2016), nevertheless the drive for CSO inclusion is real and so this article limits its scope to this specific dimension of the problematic.

Not least owing to these unclarities, the theoretical benefits and disadvantages of participation are matters of dispute and ongoing investigation (Srinivas, 2009). Despite some efforts the perceived gap between may remain - or indeed a split be reinforced - between scientific researchers and those engaged with civil society. This was perhaps evidenced on a European level with the controversial scrapping of the Bureau of European Policy Advisors (BEPA) and Anne Glover as Chief Scientific Advisor, which followed a 'war of letters' between scientific researchers and a consortium of NGOs and CSOs (Wilesdon, 2014).

This paper contributes to the debate by providing a comprehensive review of the literature of CSOs in research. It focusses mainly on European research and the European policy context as European research and its context are often very visible exponents of the participatory trend just outlined. The paper starts by discussing the potential roles of CSOs in research and underlining 
the importance of conceptual clarity when defining the input that CSOs can provide for research and the impact they can have. It then shows that there are several different bodies of literature that reflect different perspectives on CSOs. More specifically it reviews the academic literature, the literature arising from CSO-related research projects and policy literature, especially concerning European research policy as a paradigmatic case. On the basis of the analysis of these three bodies of literature, we propose that there is no one definition of CSO but that there are several distinct types. Understanding this typology will allow the development of better research policy and will increase the likelihood of successful contribution of CSOs to research.

\section{The Need for Conceptual Clarity}

\section{Public Engagement, Mode 2 and the Role of CSOs}

In order to understand why involving CSOs in research may be a policy objective, one needs to reflect on some of the fundamentals underpinning research. One very general epistemological thesis has it that for every set of phenomena, it is possible that more than one theory can provide explanation for that set. In some important respect, there is latitude for choice among these competing explanatory theories. Value, evaluation of evidence, is always present in theorymaking. A thesis like this is argued by some non-positivist theoreticians of science. Thomas Kuhn (1996) can be seen as working in this epistemological territory.

Kuhn's choice of word, 'revolution' connotes something of the political and can hardly have been a mistake. Political, social and other value agendas hitherto thought of as 'outside science' Kuhn reveals as present and active in the course of scientific advance. Gibbons et al (1994) press this line very specifically with respect to contemporary knowledge-production and the processes of research. This thesis is generally compressed to a binary distinction between 'mode 
1 ' and 'mode 2' research. The former indicates traditional views on science and knowledge production - a pre-eminence of experimental methods carried out by detached, disinterested, autonomous scientists enacting an objective method within a standard discipline. The latter, in contrast, suggested knowledge-production that is distributed among various practitioners from a potential variety of fields that may be geared toward a particular application.

Another key difference between mode 1 and 2 is in terms of accountability - Mode 1 research is accountable in terms the discipline whereas mode 2 can be held accountable by a potentially diverse group of parties, across a variety of disciplines, areas of study and other fields of interest.

Perhaps particularly because of this last point, the idea of mode 2 research gained particular traction in academic, policy and research areas as it permits the crossing of traditional disciplinary lines, and freedom to define research agendas within older and newer domains (Nowotny, Scott, \& Gibbons, 2003:179).

In a context of declining authority for established disciplines and the experts those disciplines produce, views beyond the expert need to be sought. The multi-dimensional scope for accountability too suggests that views from a breadth of sources can create valuable insight on research aims, practices, outputs and outcomes. And where political goals and values are recognised as evaluable from many perspectives, it seems a necessary step to include a democratic element in this part of mode 2 research.

The European project "Science, technology and civil society - Civil Society Organisations, actors in the European system of research and innovation" (STACS) pursues this line strongly, arguing that CSOs ought to be included in policy and research activities because, 
“...a new paradigm of knowledge is emerging, that focus on cooperation instead of competition, and on the sharing of knowledge instead of its private appropriation, CSOs can also share, bring and produce new knowledge, by getting involved in partnerships with researchers.” (E. Gall, Millot, \& Neubauer, 2009, p. 6)

While this background is now well known and various policy and research paradigms have shifted in order to accommodate it, there remain nevertheless certain unclarities within the implementation of mode 2 in practice. Among these unclarities are definitions of CSO and what counts as participation. This review draws upon material in order to clarify these areas, and to contextualise them appropriately.

\section{Definitions of CSOs}

One key issue is that a standard definition for the term 'Civil Society Organisation' is absent from extant literature (Muukkonen, 2009). This raises theoretical and empirical problems. If a definition is made that is too narrow, then the set of candidate CSO examples will be too small, which could compromise legitimacy of the knowledge or evaluation provided by the groups. On the other hand, very broad definitions comprise a too large a variety of CSOs, which are unlikely to be compatible with one another. This again raises issues of legitimacy, as well as likely causing problems for the efficiency of research efforts - a 'too many cooks' conundrum. One very broad definition is the EU's own, classifying a CSO as 'Any legal entity that is nongovernmental, non-profit, not representing commercial interests and pursuing a common purpose in the public interest'. This is arguably so broad as to fail to be informative, at least in some plausibly conceivable contexts. In addition, aside from it being so broad, it excludes those 
entities that see themselves as non-governmental, who may be legally be commercial entities but which pursue the public good, such as social enterprises.

Given its increasing prominence in European policy debates, the application of the term CSO is of central importance. Taking into account that various organisations and sectors have interests in defining CSOs, the task requires an approach that can provide an informative, and therefore potentially action-guiding, account of CSO definition.

In order to approach this issue in an open manner, a simple binary definition of the term $-x$ is/is not a CSO - is here avoided and instead a typology of CSOs is sought, to account for the diversity of organisations participating in European framework programmes. The typology is rooted in an appraisal of the perspectives evident from reflection upon academic, policy and project literature streams. This anticipates a diversity of organisations that will vary across a set of dimensions such as outcome emphasis, program area focus, legal framework and organizational type (Kerlin, 2012).

Overall, the present analysis will require two steps, one descriptive and one explanatory. The descriptive step will use a literature review from various perspectives. This will serve to give a picture of how CSO participation has been carried out or how it has been approached in research projects from a number of points of view. The explanatory step will come from an analysis of what we discover in order to explain why discussions of CSO participation have been realised in the way that they have. Together, these two steps will provide a basis for understanding present views, and suggesting revisions to enable more optimal participatory practices. These will be based on an understanding of the outputs from academic researchers, project participants and policy discourses. 
This practical benefit will come from a better understanding of sectorial definitions of CSOs. The idea here is not to find a single, 'best', definition but to make explicit the presuppositions used when 'CSO' is used in academic, policy, or project literature. In making this explicit, light will be shed on the differences and similarities between sectoral assumptions about CSOs. This will facilitate better inter-sectoral understanding, and so can ground a more reflective, judicious, and clear discourse on CSOs among academics, policy figures, and project leaders. This intersectoral understanding has been cultivated by conducting a review of literature on academic, policy and projects covering CSOs participation in research. The methodology is discussed in the section that follows.

\section{Methodology}

The purpose of the literature review is to explore and deepen the understanding of CSOs involvement in research. The review aims to clarify the nature of CSOs by reviewing academic, policy and project (e.g. deliverables) documents. These are taken as evidence of how CSOs have been perceived, and their involvement experiences, by those operating in each of the three domains. In this section, the sources used and procedures taken to obtain evidence are described, interpreted and analysed. The objectives of the systematic review task are to:

- Collect and critically analyse the term and concept of CSOs from the perspectives of disciplines and fields of practice which have interests in CSOs

- Discover working definitions as heuristics

- Allow the conceptual identification of important features and characteristics of CSOs from broad perspectives

The literature reviews here will take the form of a systematic review (Tranfield, Denyer, \& Smart, 2003). 'Systematic' reviews aim to use replicable, scientific and transparent processes, 
that permits an audit trail for the conclusions made (Tranfield et al., 2003, p. 209). In this case, the review aims to clarify the nature of CSOs by reviewing several streams of literature that are relevant to CSOs in research. This allows the collection and critical analysis of use of the term 'CSO' (and cognates) from various perspectives. The value of establishing perspectives on CSO definition is that similarity and difference can be discovered between parties to whom CSOs are important actors. In this instance, the perspectives to be explored are the academic, the policy, and those of projects. This will lead to sector-based workable definitions of CSO, and will allow the conceptual identification of important perceived features and characteristics of CSOs. From this, a typology of CSOs will be constructed.

\section{Selection of Literature}

Since a key interest is critically reviewing definitions and terminology used in relation to CSO participation in research, academic literature and research project outputs are of central importance. Given too that participative methods and CSO involvement are 'hot topics', especially in EU funding instruments such as FP7 and Horizon 2020, a critical review on relevant EU rules and initiatives in policy making is of interest too. The European funding instruments are of particular interest also as they are intersections between policy (supranational and national policy aims) academia (research applications typically come from universities) and civil society (the evolution toward 'science with and for society' and responsible innovation puts citizens centre-stage (Anichini \& Cheveigné, 2012; Dröll, 2014; Finke, 2007). This is therefore a rich environment from which to draw material for interpretation and analysis.

\section{Database Selection}


Academic articles were captured by search of academic databases (Scopus, Academic search premier (EBSCO) and Science Direct). These databases were chosen because they are leading databases, providing coverage of high quality research. To maintain relevant, good academic quality and identify sound conceptual arguments, the study focused on literature that was from peer reviewed sources, and had full text articles available. Only studies conducted from 2000 were included. This was to ensure the study is contemporary. It is also assumed that articles published within this time scale build on those previously published before 2000 .

Since the research team operates primarily in the English language, articles in other languages were avoided due to limited time and resources for translations.

Unlike with academic literature which can easily be identified in academic databases such as those outlined above, project and policy literature is somewhat restricted in that most of it is identified from documentation which may not necessarily come under peer-review scrutiny. Therefore, the documents had to be found from other channels.

The European Commission has a large and searchable database of the research projects it has funded and its broad policy discussions - the Community and Research and Development Information Service (CORDIS), a rich source for the purposes of this literature review. Projects can be selected via keyword searches and their outputs (e.g. reports, deliverables) further scrutinised. CORDIS also represents a good starting point for identifying policy literature.

\section{Selection of key terms}

Having selected literature domains, the next step was to determine keywords to be searched for in each database. Firstly, the key term, 'Civil Society Organisation' was used. However, taking into consideration the wide application of the CSO phenomenon in various disciplines, different 
geographical and economic regions, among many other institutional frameworks, the application of the term CSO may vary. In a somewhat unavoidable, but benignly, circular move literature on this area was drawn upon to understand better the kinds of cognate terms that exist for 'CSO' in differing contexts. Drawing upon literature such as the United Nations Development Panel's 'Note on Teminology' and others (TACSO, 2010; UNDP, n.d.) distinctions and similarities between 'CSO' and 'NGO' are noted, along with discussion of third sector and other not-forprofit organisations. Hence, cognate terms for CSOs such as 'non-governmental organisations' (NGOs), 'third sector organisations', and 'non-profit organisations' were also deployed, in light of the contested nature of such terminologies. These keywords were then used to search the databases of academic papers in electronic databases, and CORDIS to find EU policy literature and project outputs. The following sources resulted after removal of duplicates and irrelevant pieces:

- Academic sources, 135 documents

- Policy sources, 80 documents

- Project output sources, 111 documents

\section{Literature Analysis}

A qualitative data analysis software (NVivo Server, version 10) was used to tag the literature sources according to the following themes, themselves based on the knowledge gap identified above:

- Definition of CSO or related terms

- Expected benefits of CSO participation in research 
- Possible downsides of CSO participation in research

- Current involvement in research

- Empirical support for the main hypotheses

- Off-topic (allowing to tag papers that were included in the search but turned out not to be relevant to the research question)

Overall, this treatment of the bodies of text provides a kind of classificatory framework through which the discourse can be seen in general. This permits an overview of the flow of the discourses which can ground reflection based in texts. Using this generalising technique it is possible to draw general conclusions and deduce working hypotheses about the views of CSOs' definition and uses for each of the bodies of text in question. This approach is also very apt for replication by other researchers. This could provide a useful pool of information and interpretation for further discussion and insight in this area.

It should be noted that the literature oscillates between discussions of CSOs as participants in research, and CSOs as objects of research, sometimes showing elements of each. In a sense, this is a finding from beginning to undertake the literature review. However, classifying literatures' focus into these poles is not the point of the review. We try to make it clear that we are talking about how the literature talks about CSOs, and from this to draw conclusions about CSOs in various contexts. This is not a simple position to take, or to describe, but it is a valuable one in clarifying contexts of action for CSOs, as well as for academics, policymakers, and project participants.

\section{Findings}

\section{CSOs in the Academic Discourse}


Having analysed the database of academic literature, we can see how our preliminary findings relate to the views of CSOs.

For example, focusing on the academic article "Effects of Civil Society Involvement on Popular Legitimacy of Global Environmental Governance." (Bernauer \& Gampfer, 2013b), the theme such 'Benefits' of CSO involvement in research, relates to 'Capacity building', 'Empower', and 'Increase transparency'. This allows an overview of the ways in which CSOs are discussed in this one academic source, i.e. here, CSOs' involvement in research is given as a benefit in terms of capacity-building, empowerment, and transparency.

For each of the academic articles, this classifying through tagging terms and sections of text can be done to reveal in detail the landscape of CSO discussion across the literature stream. This principle applies to each domain of literature, and so this can be seen as the principle upon which general views of domain discourse can be synthesised.

One interesting dimension of analysis here is the distribution of tagged themes across the literature; the frequency of the themes' emergence and discussion. When analysis of this kind of distribution is made, it shows a relatively even distribution of discussion of the themes mentioned above among the sources. This suggests that the themes that underlie CSO discussion arise fairly evenly throughout the discourse. Specifically in relation to the academic discourse, this approach suggests is a fairly settled discussion on CSOs, spread among sources, rather than skewed by sustained discussions in particular sources. This approach grounds the formation of a perspective on how different discourses on CSOs follow a general pattern. In other words, using analysis of how literatures have CSO themes distributed throughout their discussions will let us model, in an informed way, what a generalized academic, policymaker or project member thinks 
about when she thinks about CSOs. This will ground a generalized perspectival definition of CSO for each sector. This will provide a basis for further analysis and interpretation.

Most broadly dwelt upon in the academic literature are the benefits of CSO involvement in research. Specifically, the general academic is interested in the advocacy and opposition to authority potential represented by CSOs. This oppositional potential is mostly considered in terms of the strengthening of democracy, i.e. where CSOs represent entities capable of ensuring light touch regulation of science by political or bureaucratic agendas. More disparate discussion in the academic literature involves a similar watchdog type of role for CSOs, but in terms of scientific conduct and agendas. CSOs are discussed in terms of monitoring social justice of scientific research, considering fair distribution of resources, inclusion of values in scientific research and community engagement.

Given this array of activities, definitions of CSOs are clearly of interest to academic discussions. Academic discuss the definition mainly in terms of CSOs' non-governmental, non-profit, selfconstituting, voluntary association status. The voluntary nature of the organisations couples with a varied discussion of CSOs as partners of donors and state organs, elaborating upon their nongovernmental nature.

Also looming large in the academic discussion of CSO definition, given these complex state/donor/society responsibilities is the legal status of CSOs. In this context, the discussion of cognate terms besides 'CSO' arises. NGO, for instance, is discussed as indicating the legal status of the group whereas CSO is considered as indicating the constituency and aim of the organisation. 
Different emphases upon different aspects of CSO definition impact upon downsides of CSO involvement, as considered by academics. The main focal point concerns legitimacy of CSOs' involvement, especially given constraints imposed upon such involvement by political realities and donor conditions. CSOs can be buffeted amid conflicting value agendas, and can be fairly powerless to pursue agendas within research given these constraints. Especially where low levels of citizen involvement occur, this is discussed as a problem of practical or technical efficacy, or as an issue concerning trust in CSOs as effective and representative bodies in research.

The main constraints upon CSO involvement in research are elaborated upon in terms of the unfavourable legal and political conditions they might find themselves subject to. Key to this, for academics, is the funding régimes CSOs operate under. The scarcity, as well as the short-term nature, of funding for organisations constrains the operational capacity in many ways that lead to the downsides of CSO-research involvement just discussed. The ability for CSOs to set research agendas, both at project and higher levels, is a condition that leads to constraints.

Academic discourse is concerned that the constraints upon research that lead to some of these downsides prevent in many cases CSOs from contributing as they might otherwise to positively impacting on networks, collaborations and training, as well as impeding the dissemination of scientific benefits and other messages to CSO constituents.

With these general overviews briefly stated, the business of CSO definition can now be turned to using the same principle as has been shown so far - assessing preoccupations within literature under certain themes.

\section{Definition of CSO - Academic literature}


Within the selection of academic literature a broad discussion of CSO definition is captured. The variety of discussion given over specifically to CSO definition is evident. Coming from the literature are terms such as voluntary association, non-profit, and so on that indicate some of the contents of various perspectives on CSO definition. These terms help us to get a sense of the normative backdrop to academic discussion in this area. This helps us to dig down to a level that will facilitate the modelling of academic perspectives on CSO definition. It also proves a principle that will be applied to policy discourse and research projects. Using these methods, mining the literature in this way, the modelling of these perspectives will be enabled. The preoccupation in the stream of academic text shows the general parameters for what an academic thinks of a CSO. This is useful in helping to clarify academic discourse about CSOs. It shows how a generalized academic conceives of CSOs, and as such it can serve to make explicit an otherwise tacit framing of CSOs from this perspective. For one thing, a framing will partly determine why and how an academic would include a CSO in a research project. This will also play a role in what kinds of organisations are sought out for inclusion in research by an academic. Gaining insight on this perspectival information is of great value in understanding the context in which CSOs operate. This is of more value, we argue, than simply rejecting one definition of CSO in favour of another.

For policy and project literatures, the same principle will be applied, and the three literature streams compared.

\section{CSOs in Policy Discourse}

The policy discourse is centred on matters of current CSO involvement in research and the benefits of CSO involvement in research. Within the discussions of CSO involvement it can be seen that reasons for including CSOs are widely discussed, alongside CSO roles, constraints and 
enablers, and impact on research. The most prominently discussed benefits are the enabling of citizen participation in research and the quality of research itself. Perhaps most strikingly of all is the variety of discussion indicated by the profusion of terms falling under the broad preoccupations.

Part of the suggested roles for CSO participation within the policy discourse has to do with climate change. The policy discourse suggests that climate change is an important area of participation for CSO. For example, the CASI policy briefs (Bailey, 2010; Chonkova et al., 2014; Gecas, Matschoss, Kaarakainen, Repo, \& Tregner-Mlinaric, 2014; Lipnik, Matschoss, Kaarakainen, Repo, \& Tregner-Mlinaric, 2014; Piotrowicz, Matschoss, Kaarakainen, Repo, \& Tregner-Mlinaric, 2014; Popper et al., 2014) that although some policy areas may be more the responsibility of government, other areas such as climate change call for joint responsibility with CSOs and other stakeholders industry, local government and communities playing important roles. Policy literature also discusses the benefits of involving CSOs in science and technology research in that it is not only beneficial to society and ensures that with the involvement of CSOs, society has the opportunity to give input on not only how it might impact on it in a positive way and also look at the risks in a much more holistic way (Council of the European Union, 2010).

The implication of this discussion is that science and technology research no longer is the preserve of elite entities like research institutes or policy makers but is all inclusive, consultative and participatory. The discourse, further suggests that such society engagement can only help to promote transparency and overcome mistrust towards science and technology which can often be a present factor (Tsipouri, 2012b). Tsipour has further argued for policy with a strong Science in Society agenda with CSOs at its heart without whom any scientific policies could be rendered 
ineffective. In order to avoid such scenarios, it is perhaps unsurprising that the European Commission for instance has funded the VOICES project which is a European network of science centres and museums where citizens have been called to participate and give input on the science and technology urban waste policy (Broerse, Lynch, \& van der Ham, 2013; Kupper, Den Oudendammer, van der Ham, \& Cummings, 2013). Furthermore, statements such as the one below which is highlighted in the proposal for a regulation of the European Parliament and the council in establishing Horizon 2020 - The Framework Programme for Research and Innovation (2014-2020) (European Commission, 2011b) shows how keen policy makers are to involve CSOs in research and how important and beneficial they view their input is. At the core of this ambition is the fact that the involvement of civil society can make science more accessible to citizens and that research agendas involving citizens ought to be open and responsible to the needs of citizens and society as a whole.

\section{Definition of CSOs - Policy discourse}

Pursuing CSO definitions from this literature stream shows that the discussions of CSOs in policy literature are cognate with standard EC definitions. What is of interest is the limited scope and emphasis suggested in the policy discourse. With policy discourse, terms that connote CSO are used interchangeably. In one instance, NGOs can be used to mean CSOs, in another instance the term non-profit or not-for-profit is used in place of CSO. This suggests a lack of coherence in policy terms with regards to what CSOs might mean - a looseness in discussion. As a result, the implication is that the definition of CSOs might be too broad or even exclusive which may be a disadvantage when considering the role that CSOs are likely to play in and for society. Common cause NGOs, non-governmental and non-profit definitions dominate the discussion. From this, we might conclude that policy discourse, when it turns to CSOs, conceives of them in these 
terms. How a policy perspective conceived of CSOs will frame how policy is made concerning CSOs - this capturing of a perspective is therefore of value in helping to evaluate policy on CSOs.

\section{CSOs in Project Outputs}

Strikingly, project outputs discuss CSOs' current involvement in research about as much as they discuss definitions of CSOs, benefits of CSO inclusion, downsides of inclusion and empirical support combined. In terms of current involvement in research, project outputs tend to discuss constraints on CSO participation, especially possibilities of underappreciation and miscommunication concerning CSOs in research consortia.

The specific roles occupied by CSOs in research consortia as disseminators of findings and as agenda-setting partners are broadly discussed, as is a general role for CSOs as both subject and object of research. These complex roles are modes of participation point to the unsettled nature of discourse surrounding CSO participation in research, but also delineates somewhat the scope of the problem: CSOs are seen in project outputs as collaborative partners and as targets of research; influencers of research and testers of research outcomes. Overall, the discussion in project literature of current involvement in research is wide-ranging and varied. This in itself hints at the multiplicity of expectations and implementations that CSO participation in research brings. There appears to be no simple account of this participation. Perhaps accounting for CSO participation would involve at least two steps - accounting for CSOs, and then accounting for 'participation'. Given the lack of consensus for CSO definition (or even for whether definition is the most fruitful route to take), we could expect that this would be reflected in an exploration of participation too. Thus the problem would be compounded. These are suspicions for now, as this 
investigation of CSOs through a lens of participation is a necessary one, but somewhat outside the scope of the current paper.

However disparate the discussion of CSO involvement may be, far clearer is that of the benefits of such participation. In the project literature, six main benefits emerge in the discussions capacity-building, dissemination, providing local knowledge, transforming the system to become more responsive, multi-dimensional legitimacy and research appear equally weighted in terms of the benefits brought by CSO participation in research. Related benefits widely discussed seem to be variations on themes emerging from this list, for instance, CSO participation offers new perspectives, the articulation of values and the scope to work on the social acceptability of scientific research. That these benefits appear so clearly in the discussions, whilst modes of participation are so finely grained, points to the many ways participation can manifest. But this also points to the value of participation, however it is done.

The project literature is not one-sided, however, and significant discussion surrounds the potential downsides attending CSO participation in research. Three main areas of discussion seem to cluster around the theme of legitimacy - CSO participation has no particularly welldefined means of evaluation, the relevance of CSOs can vary and researchers and CSOs can operate on widely divergent principles. These problematic areas suggest that project researchers are concerned with the ways in which CSO participation can inhibit research per se in being a problematic add-on to otherwise well-defined work.

On the other hand, a downside for CSOs also emerges in the discussion in terms of access to funding. Rather than CSO participation potentially jeopardising scientific research, project outputs recognise fairly strongly that CSOs themselves can be inhibited in their action owing to 
unreliable funding structures. Evidence for this arises in project outputs with reference to issues in the makeup of funding calls, the proper acknowledgement of CSO input to research work and to the ability to overlook CSOs in research planning. Overall, the research project outputs appear to acknowledge the benefits of CSO participation in quite an emphatic way, but there are concerns over the 'how': How to include and evaluate CSOs effectively, and how to ensure that CSOs can provide their input effectively.

\section{Characteristics of CSOs - Project outputs}

According to the general discourse within project literature, given the preoccupations and talking points that seem to emerge in terms of CSO definition, projects tend to view CSOs in terms of non-governmental, non-profit and no commercial interest, faith-based association or those with alternative legal status. Projects recognize the complexity of CSO identity as having no straightforward, single definition but they tend to orient themselves to public interest or public well-being. There is a clear difference in terms of how CSOs are viewed in projects in that while there are some definitions provided in academic and policy discourse, albeit not straight-forward ones, projects will tend to avoid outright definitions and rather concentrate on what CSOs are supposedly about and what they stand for, which is to realise social good for society.

\section{Synthesis of Definitions of CSOs}

With these overviews of academic, policy and project output discourses, in terms of general preoccupations in discussing CSOs and their identity, further abstraction is possible.

Interestingly, a picture emerges of discussion of CSOs that appears consistent but not identical among academic, project and policy discourse. Nevertheless, despite overlapping themes, the views of CSOs in the three bodies of literature are substantially different. This table shows the 
$\mathrm{EC} / \mathrm{EU}$ view, the academic view; the policy view and now the emerging project view, based on the most widely discussed themes from project outputs:

[Table 1: Working CSO definitions]

\section{A CSO typology}

Respecting the diversity in views among perspectives on CSOs, a CSO typology is in order. A simple definition will not capture the variety found in the literature. With the views developed here, it will become increasingly fruitful to look at the CSOs in terms of the predicates that arise from various discussions, combined to form distinct types of CSO. The typology we propose synthesizes the perspectives on CSOs, their definitions, and their uses, from the three literature streams surveyed. Each one of the bodies of literature is linked to one of the types depending upon how that literature stream emphasized different dimensions of CSOs. We also propose a fourth type that covers an obvious gap that is not discussed in the literature we surveyed. This is a more commercially-oriented CSO type, excluded from the discussions by being related to profit-making organisations, although not themselves necessarily profit-centred entities.

This is highly informative for ongoing research as it allows for the opening of the concept 'CSO' and enriches the scope of questions like, "What is a CSO?" These parameters can be directly mined from this literature review, the analytical standpoint taken in it, and the typology.

\section{Typology of CSOs}

Taking into account all of the above, the following table has been synthesised that gives a principled overview of types of CSOs according to a range of dimensions derived from the literature reviews. The definitions of CSOs from each domain of literature are drawn upon, as are 
the general preoccupations of the literature domains, i.e. the sorts of themes that CSOs are discussed under according to academic, policy, and project literature.

[Table 2: Preoccupations in literature reviews]

This table is based in the synthesis of the above literature reviews' outcomes concerning definition and broader understanding of CSOs' participation in research. These are 'tags' for types of issues widely discussed in each body of literature, providing insight on how CSO action is thought of in the literature (e.g. CSO motivators, interests, values). This can be instrumental in generating criteria for understanding types of CSOs. It does this by homing in on key interests for better understanding the perception and experiences, expectations and presuppositions concerning CSOs from the three domains.

\section{[Table 3: Typology of CSOS]}

In synthesising a typology of CSOs in this way, a basis is provided for either pursuing themes that preoccupy current projects, or grounding a gap analysis and finding interestingly understudied cases. Uniformities or divergences alike will be illustrative of types of CSOs through highlighting their action logic, or the logic imposed upon them in participation by other groups, relating to how these other groups frame CSOs. We can see how CSOs are discussed from the perspectives of the literatures analysed. A literature-review grounded typology of CSOs should be of interest to all parties interested in CSO participation in research and related areas.

\section{Better understanding the area}


One further, extremely useful application of this literature review and analysis is to provide additional insights that will give a better basis for understanding and grounding decisions concerning CSOs and research. Drawing upon the notion of an action logic as developed above, sensitivity to the fine-grained nature of interests and objectives will permit accurate and ultimately more powerfully compelling views of possible CSO participation. For example, the above analysis reveals that policy discourses on CSO involvement in research focus on current involvement and benefits of that involvement. Whilst academic discourse typically sees common ground in being preoccupied with benefits, it also diverges in being nearly as concerned with definitions of CSOs. Downsides to CSO involvement in research also appear prominently in academic discourse in a way not mirrored in policy discourse. Such information is, of course, invaluable in terms of modelling the actions, behaviours and preferences for these discourses in general.

\section{Conclusion}

A central problem affecting the understanding of CSO participation in scientific research stems from lack of clarity of definitions and the nature of participation. The motives for CSO participation, whilst not uncontroversial, can be reconstructed from the literature-perspectives shown above. This work has sought to provide a means to address the unclear parts of the CSO participation field. It has done this through a systematic review of key literature streams and an analysis of results therefrom. From this, a typology emerges providing a basis for reconstructing action logics for CSOs.

\section{Contribution}

'Boundary conditions' here can be thought of as contextual constraints upon interpretations and decision-making concerning CSO participation in research. To make a parallel, one could say 
that ceteris paribus a ball will roll down an inclined plane. If, however, it is revealed that the ball is glued to the surface and so does not roll, the basis for the prediction being wrong lies in the lack of knowledge of the boundary conditions. By analogy, the positions of academics, policymakers, researchers and so on will have different boundary conditions and normative anchor points. These internal boundary conditions and normative anchor points will structure the responses to information made by the modelled agent and so the rich understanding of them, facilitated in the literature review, will allow informed predictions about the modelled agents when that part of the research arises.

The article attempts to avoid problems of definition by developing a typology, which was intended to be more dynamic and instrumental than a simple is/is not a CSO definition. The typology, as an instrument, may help to mitigate a set of CSO selection problems in that it recommends a varied set of potential partners for consortium-based research that is based in the perception among research partners of CSOs (and others). To this extent, it represents a positive input to a diversification agenda, and whilst it is not itself the final word in this area there are benefits to be reaped from a clear view of potential research partners and their associated roles in research projects.

One last application of this technique is that the overall, general discourse on CSOs in research can be modelled in the sense of showing the preoccupations of all three aspects here studied, aggregated together. The results demonstrate that 'current involvement in research' is by far the most discussed aspect of CSOs in research, seeing more than eight times the references than the next most common discussion on the downsides of that involvement. Empirical evidence of CSOs in research and the definition of CSOs come next in terms of frequency of discussions, 
followed by discussion of various specific areas of benefit, such as research quality, enabling citizen participation in science and capacity building.

The point overall is that through using the techniques and tools here discussed a very flexible and informative means of gaining insight to the very poorly understood area can be developed. In terms of (Salamon \& Sokolowski, 2016) this intended contribution might be seen as increasing breadth, sensitivity, and clarity of the conceptualization of CSOs engaging in research.

These results are valuable in themselves, but also replicable in a way that permits the deployment of different interpretive strategies or literature streams. In this, the foregoing work opens a door on a pressing problem while at the same time delivering material that can substantiate a response to that problem. CSOs, their definitions and perceptions, standard roles, ambitions and places in scientific research are clarified in this work. The typology provides this material. Scope for further developments is also broadened, in showing as clearly as possible the potential of software-facilitated, systematic literature review.

\section{Limitations, next steps}

The value of this work is in its generality, but this is a double-edged sword. As focus is pulled to reveal general insights, less detail can be discerned. There is therefore a balance to be struck between the insights gained broadly, versus those of detailed knowledge.

This article remains at a level of abstraction whose main elements are 'partner organisations', 'consortia', 'funders' and so on. This means it presents a somewhat programmatic take on research projects at the level of research design, or research consortium construction. The nitty gritty of actual participation is of course research-project defining: this is more fertile ground that 
ought to be explored. The article nonetheless contributes to the discourse by presenting this high level view, against which more fine-grained observations may be contrasted.

The scope of the research here is limited to the extent that it is predominantly in the European policy context, and the literatures explored are in English. Globally, there are many instances of CSOs in research of different types, in different regulatory frameworks (Engage2020 Consortium, n.d.). An interesting move would be to replicate the approach here in other contexts and languages in order to gain a clearer vision of CSO perceptions and activities in research globally. This journal has already devoted considerable space to the third-sector situation globally, such as in China for example (Brandsen \& Simsa, 2016). Being in the European context also means that project literature in particular is largely based on large, consortia-driven projects. There are lots of other types of research in which CSOs feature, such as grassroots, local, national and community research initiatives. If these areas could be captured by another instance of the kind of technique detailed here, a great deal could be learned about this mode of research and these research stakeholders.

Whilst the focus of this article is on a typology, as a remedy to a binary definition of 'CSO', there are issues to be found with the ways in which CSOs, howsoever defined, ought to be thought of as participants - the uses and expectations of CSOs as actors in a broader context, for instance in terms of contributions to civility or civic culture (Dekker, 2009). A broader reflection on such matters could have interesting ramification for the implication of CSOs in research, although it has been out of scope in the present article.

The format of CSO participation in research is another area in need of scrutiny, which is connected to how CSOs are perceived, but has its own appreciable context. This could form a 
focus for further research focused upon the functioning of research actions, rather than the context of their construction which has been more generally under scrutiny here.

Finally, the idea of modelling agents could be a fruitful path to follow, although it is out of scope in the present work. While the notion of boundary conditions and normative anchor points is here described, we cannot run with the idea, but suppose that this would be an interesting next step.

\section{Acknowledgements}

This research is a development from work carried out in the research project, "Network Analysis of Civil Society Organisations' Participation in Research Framework Programmes," led by The Institute for Managing Sustainability at the University of Vienna, and funded by the European Commission.

We would like to acknowledge the important contribution made by Dr. Brent Mittelstadt in the design of the literature review approach and Mr. Shingirayi Kandi in doing the initial coding. 


\section{References}

Anichini, G., \& Cheveigné, S. de. (2012). Overview of research related to science in society in Europe. Science and Public Policy, 39(6). https://doi.org/10.1093/scipol/scs088

Bailey, C. (2010). The European Discourse in Germany, 1939-1950: Three Case Studies. German History, 28(4). Retrieved from http://search.ebscohost.com/login.aspx?direct=true\&AuthType=ip,shib\&db=aph\&AN=5 5370438\&site=ehost-live

Bernauer, T., \& Gampfer, R. (2013a). Effects of civil society involvement on popular legitimacy of global environmental governance. Global Environmental Change, 23(2), 439-449. https://doi.org/10.1016/j.gloenvcha.2013.01.001

Bernauer, T., \& Gampfer, R. (2013b). Effects of civil society involvement on popular legitimacy of global environmental governance. Global Environmental Change, 23(2). https://doi.org/10.1016/j.gloenvcha.2013.01.001

Brandsen, T., \& Simsa, R. (2016). Civil Society, Nonprofit Organizations, and Citizenship in China: An Editorial Introduction to the China Issue. VOLUNTAS: International Journal of Voluntary and Nonprofit Organizations, 27(5), 2011-2020. https://doi.org/10.1007/s11266-016-9774-4

Broerse, J. E. W., Lynch, D. H. L., \& van der Ham, L. (2013). Country Report Bulgaria: Views, Opinions and Ideas of Citizens in Europe on Science. Retrieved from http://www.voicesforinnovation.eu/files/Contry_Report_x_web/CountryReport_Bulgari a.pdf 
Chonkova, B., Kozarev, V., Matschoss, K., Kaarakainen, M., Repo, P., \& Tregner-Mlinaric, A. (2014). CASI Policy Brief: The Eco-innovation Action Plan in an environmental policy context - Insights from and for Bulgaria. Retrieved from http://www.casi2020.eu/app/web1/files/download/casi-pb-national2-bulgaria-final.pdf

Council of the European Union. (2010). Commission Staff Working Document: Europe 2020 public consultation overview of responses.

Dekker, P. (2009). Civicness: From Civil Society to Civic Services? VOLUNTAS: International Journal of Voluntary and Nonprofit Organizations, 20(3), 220-238. https://doi.org/10.1007/s11266-009-9089-9

Dröll, P. (2014). HORIZON 2020 "SCIENCE WITH AND FOR SOCIETY” PROVIDING ADVICE ON POTENTIAL PRIORITIES FOR RESEARCH AND INNOVATION IN THE WORK PROGRAMME 2016-2017 CONSULTATION PAPER. European Commission. Retrieved from http://ec.europa.eu/research/consultations/swafs/background.pdf

Engage2020 Consortium. (n.d.). Active societal engagement in research and innovation: Exploring what is happening today and inspiring tomorrow's practice (Poster). Retrieved January 13, 2015, from http://engage2020.eu/media/Engage2020-Poster.pdf

European Commission. (2011a). Horizon 2020 - The Framework Programme for Research and Innovation (No. SEC(2011) 1427 final). Brussels. Retrieved from http://ec.europa.eu/research/horizon2020/pdf/proposals/communication_from_the_c ommission_-_horizon_2020__the_framework_programme_for_research_and_innovation.pdf\#view=fit\&pagemode= none 
European Commission. (2011b). Horizon 2020 - The Framework Programme for Research and Innovation. Brussels. Retrieved from http://ec.europa.eu/research/horizon2020/pdf/proposals/communication_from_the_c ommission_-_horizon_2020__the_framework_programme_for_research_and_innovation.pdf\#view=fit\&pagemode= none

European Commission. (2012). Monitoring Policy and Research Activities on Science in Society in Europe (MASIS) - Final synthesis report. Brussels: Directorate-General for Research and Innovation. Retrieved from http://ec.europa.eu/research/sciencesociety/document_library/pdf_06/monitoring-policy-research-activities-on-sis_en.pdf European Science Foundation. (2013). Science in Society: caring for our futures in turbulent times (Science Policy Briefing No. 50). European Science Foundation. Retrieved from http://www.esf.org/fileadmin/Public_documents/Publications/spb50_SciencelnSociety. pdf

Finke, B. (2007). Civil society participation in EU governance. Retrieved from http://edoc.vifapol.de/opus/volltexte/2011/2479/pdf/Ireg_2007_2Color.pdf

Gall, E., Millot, G., \& Neubauer, C. (2009). Participation of Civil Society Organisations in Research. Retrieved from http://www.livingknowledge.org/livingknowledge/wpcontent/uploads/2011/12/STACS_Final_Report-Partic.research.pdf

Gall, É., Neubauer, C., Millot, G., \& Piasecki, F. (2011). STACS Handbook For CSOs. Retrieved from http://sciencescitoyennes.org/wpcontent/uploads/2011/09/STACS_HandbookForCSOs.pdf 
Gecas, K., Matschoss, K., Kaarakainen, M., Repo, P., \& Tregner-Mlinaric, A. (2014). CASI Policy Brief: The Eco-innovation Action Plan in an environmental policy context, Insights from and for Lithuania. Retrieved from http://www.casi2020.eu/app/web1/files/download/casi-pb-national2-lithuania-final.pdf

Gibbons, M., Limoges, C., Nowotny, H., Schwartzman, S., Scott, P., \& Trow, M. (1994). The New Production of Knowledge: The Dynamics of Science and Research in Contemporary Societies. London: SAGE Publications.

Gómez-Jauregui, J. (2004). The Feasibility of Government Partnerships with NGOs in the Reproductive Health Field in Mexico. Reproductive Health Matters, 12(24), 42-55. https://doi.org/10.1016/S0968-8080(04)24146-5

Kerlin, J. A. (2012). Defining social enterprise across different contexts: A conceptual framework based on institutional factors. Nonprofit and Voluntary Sector Quarterly, 42(1), 84-108.

Kuhn, T. S. (1996). The structure of scientific revolutions (3rd ed). Chicago, IL: University of Chicago Press.

Kupper, F., Den Oudendammer, W. M., van der Ham, L., \& Cummings, L. (2013). Country Report Cyprus: Views, Opinions and Ideas of Citizens in Europe on Science. Retrieved from http://www.voicesforinnovation.eu/files/Contry_Report_x_web/CountryReport_Cyprus .$p d f$

Lipnik, A., Matschoss, K., Kaarakainen, M., Repo, P., \& Tregner-Mlinaric, A. (2014). CASI Policy Brief: The Eco-innovation Action Plan in an environmental policy context - Insights from and for Slovenia. Retrieved from http://www.casi2020.eu/app/web1/files/download/casi-pb-national2-slovenia-final.pdf 
Mercer, C., \& Green, M. (2013). Making civil society work: Contracting, cosmopolitanism and community development in Tanzania. Geoforum, 45, 106-115. https://doi.org/10.1016/j.geoforum.2012.10.008

Muukkonen, M. (2009). Framing the Field Civil Society and Related Concepts. Nonprofit and Voluntary Sector Quarterly, 38(4), 684-700.

Nowotny, H., Scott, P., \& Gibbons, M. (2003). Introduction: 'Mode 2' Revisited: The New Production of Knowledge. Minerva, 41(3), 179-194. https://doi.org/10.1023/A:1025505528250

Piotrowicz, M., Matschoss, K., Kaarakainen, M., Repo, P., \& Tregner-Mlinaric, A. (2014). CASI Policy Brief: The Eco-Innovation Action Plan in an Environmental Policy Context, Insights from and for Poland. Retrieved from http://www.casi2020.eu/app/web1/files/download/casi-pb-national2-poland-final.pdf

Popper, M., Martin, F., Matschoss, K., Kaarakainen, M., Repo, P., \& Tregner-Mlinaric, A. (2014). CASI Policy Brief: The Eco-innovation Action Plan in an environmental policy context Insights from and for Czech Republic. Retrieved from http://www.casi2020.eu/app/web1/files/download/casi-pb-national2-czech-republicfinal.pdf

Revel, M., Spruyt, E., \& Soubiran, T. (2012). FP7 Survey Report: CONSIDER. Deliverable 2.2. Retrieved from http://www.consider-project.eu/wp-content/uploads/2012/04/D2.2FP7-Survey-report-final.pdf 
Salamon, L. M., \& Sokolowski, S. W. (2016). Beyond Nonprofits: Re-conceptualizing the Third Sector. VOLUNTAS: International Journal of Voluntary and Nonprofit Organizations, 27(4), 1515-1545. https://doi.org/10.1007/s11266-016-9726-z

Scholz, I. (2005). Environmental Policy Cooperation among Organised Civil Society, National Public Actors and International Actors in the Brazilian Amazon. European Journal of Development Research, 17(4), 681-705. https://doi.org/10.1080/09578810500367466

Smismans, S. (2008). New Modes of Governance and the Participatory Myth. West European Politics, 31(5). https://doi.org/10.1080/01402380802234540

Srinivas, N. (2009). Against NGOs? A critical perspective on nongovernmental action. Nonprofit and Voluntary Sector Quarterly, 38(4), 614-626.

Steen-Johnsen, K., Eynaud, P., \& Wijkström, F. (2011). On Civil Society Governance: An Emergent Research Field. VOLUNTAS: International Journal of Voluntary and Nonprofit Organizations, 22(4), 555-565. https://doi.org/10.1007/s11266-011-9211-7

TACSO. (2010, September). A GLOSSARY OF TERMS FOR CIVIL SOCIETY ORGANISATIONS. Retrieved from http://tacso.org/doc/TACSO\%20Glossary\%20for\%20CSOs.pdf Tomlinson, B. (2013). WORKING WITH CIVIL SOCIETY IN FOREIGN AID POSSIBILITIES FOR SOUTH-SOUTH COOPERATION? United Nations Development Programme. Retrieved from http://www.cn.undp.org/content/dam/china/docs/Publications/UNDPCH03\%20Annexes.pdf

Tranfield, D. R., Denyer, D., \& Smart, P. (2003). Towards a methodology for developing evidence-informed management knowledge by means of systematic review. British Journal of Management, 14, 207-222. 
Tsipouri, L. (2012a). Comparing innovation performance and science in society in the European member states. Science and Public Policy, 39(6), 732-740.

https://doi.org/10.1093/scipol/scs091

Tsipouri, L. (2012b). Comparing innovation performance and science in society in the European member states. Science and Public Policy, 39(6). https://doi.org/10.1093/scipol/scs091

UNDP. (n.d.). NGOs AND CSOs: A NOTE ON TERMINOLOGY. United Nations Development Programme. Retrieved from http://www.cn.undp.org/content/dam/china/docs/Publications/UNDPCH03\%20Annexes.pdf

Wilesdon, J. (2014, November 13). Juncker axes Europe's chief scientific adviser. The Guardian. London. Retrieved from http://www.theguardian.com/science/politicalscience/2014/nov/13/juncker-axes-europes-chief-scientific-adviser 
Figures and Tables 
[Table 1: Working CSO definitions]

\begin{tabular}{|c|c|c|c|}
\hline EC/EU View & $\begin{array}{l}\text { Working Academic } \\
\text { View }\end{array}$ & $\begin{array}{l}\text { Working Policy } \\
\text { View }\end{array}$ & $\begin{array}{l}\text { Working Project } \\
\text { View }\end{array}$ \\
\hline non-State & non-governmental & non-governmental & non-governmental \\
\hline not-for-profit & non-profit & non-profit & $\begin{array}{l}\text { non-profit / no } \\
\text { commercial interest }\end{array}$ \\
\hline non-partisan & --- & & --- \\
\hline nonviolent & --- & & --- \\
\hline $\begin{array}{l}\text { through which people } \\
\text { organise to pursue } \\
\text { shared objectives and } \\
\text { ideals }\end{array}$ & $\begin{array}{l}\text { self-constituting, } \\
\text { voluntary } \\
\text { associations }\end{array}$ & $\begin{array}{l}\text { Common cause } \\
\text { NGOs }\end{array}$ & $\begin{array}{l}\text { faith-based } \\
\text { association / } \\
\text { alternative legal } \\
\text { status }\end{array}$ \\
\hline $\begin{array}{l}\text { political, cultural, } \\
\text { social or economic }\end{array}$ & --- & & $\begin{array}{l}\text { no single definition } \\
\text { (?) / think tanks }\end{array}$ \\
\hline $\begin{array}{l}\text { promotes the public } \\
\text { good }\end{array}$ & --- & & $\begin{array}{l}\text { public interest / } \\
\text { public well-being }\end{array}$ \\
\hline
\end{tabular}


[Table 2: Preoccupations in literature reviews]

\begin{tabular}{|c|c|c|}
\hline Academic Literature & Policy Literature & Project Literature \\
\hline $\begin{array}{l}\text { Benefits } \\
\text { Current involvement in }\end{array}$ & $\begin{array}{l}\text { current CSO involvement in } \\
\text { research }\end{array}$ & $\begin{array}{l}\text { constraints on CSO } \\
\text { participation }\end{array}$ \\
\hline $\begin{array}{l}\text { research } \\
\text { Downsides }\end{array}$ & $\begin{array}{l}\text { benefits of CSO involvement } \\
\text { in research }\end{array}$ & $\begin{array}{l}\text { activities and impacts of } \\
\text { CSOs in research }\end{array}$ \\
\hline Capacity building & reasons for including CSOs & motivations of CSOs \\
\hline Empower & CSO roles & \\
\hline Increase transparency & $\begin{array}{l}\text { constraints and enablers } \\
\text { impact on research } \\
\text { enabling citizen participation } \\
\text { quality of research }\end{array}$ & \\
\hline
\end{tabular}


[Table 3: Typology of CSOS]

\begin{tabular}{|c|c|c|c|c|}
\hline Name & Common cause & Shared voice & $\begin{array}{l}\text { Research- } \\
\text { oriented }\end{array}$ & $\begin{array}{l}\text { Commercially } \\
\text { oriented }\end{array}$ \\
\hline Definition & $\begin{array}{l}\text { The focus of a } \\
\text { common cause } \\
\text { CSO is to } \\
\text { contribute to the } \\
\text { public good. }\end{array}$ & $\begin{array}{l}\text { The academic } \\
\text { literature } \\
\text { concentrates on how } \\
\text { CSOs are constituted } \\
\text { to express or support } \\
\text { a particular position }\end{array}$ & $\begin{array}{l}\text { The question is } \\
\text { how CSOs } \\
\text { participate in } \\
\text { research. }\end{array}$ & $\begin{array}{l}\text { Promote interest } \\
\text { of companies or } \\
\text { industries but } \\
\text { are not } \\
\text { themselves } \\
\text { profit making } \\
\text { organisations }\end{array}$ \\
\hline Source & $\begin{array}{l}\text { EU-based / } \\
\text { policy literature }\end{array}$ & Academic literature & Project outputs & $\begin{array}{l}\text { Not in the } \\
\text { literature }\end{array}$ \\
\hline Example & $\begin{array}{l}\text { AGE Platform } \\
\text { Europe } \\
\text { http://www.age- } \\
\text { platform.eu/ }\end{array}$ & $\begin{array}{l}\text { Greenpeace } \\
\text { http://www.greenpea } \\
\underline{\text { ce.org.uk/ }}\end{array}$ & $\begin{array}{l}\text { IARS } \\
\underline{\text { http://www.iars.or }} \\
\text { g.uk/ }\end{array}$ & $\begin{array}{l}\text { ACEA } \\
\underline{\text { http://www.acea }} \\
\underline{\text { be/ }} \\
\text { CSR Europe }\end{array}$ \\
\hline $\begin{array}{l}\text { Terminol } \\
\text { ogy }\end{array}$ & $\begin{array}{l}\text { CSO, not for } \\
\text { profit, NGO }\end{array}$ & $\begin{array}{l}\text { NGOs } \\
\text { Voluntary } \\
\text { associations }\end{array}$ & $\begin{array}{l}\text { Faith-based / } \\
\text { values }\end{array}$ & Sector specific \\
\hline Area of & Environment & Environment & Research & Promote the \\
\hline
\end{tabular}




\begin{tabular}{|c|c|c|c|c|}
\hline activity & $\begin{array}{l}\text { Sustainable } \\
\text { development } \\
\text { Research and } \\
\text { innovation }\end{array}$ & $\begin{array}{l}\text { Sustainable } \\
\text { development } \\
\text { Economic } \\
\text { development }\end{array}$ & $\begin{array}{l}\text { Ethics } \\
\text { Oversight }\end{array}$ & $\begin{array}{l}\text { interests of a } \\
\text { group } \\
\text { organisations } \\
\text { with a profit } \\
\text { interest }\end{array}$ \\
\hline $\begin{array}{l}\text { Properties } \\
\text { / } \\
\text { characteri } \\
\text { stics }\end{array}$ & $\begin{array}{l}\text { Non- } \\
\text { governmental } \\
\text { Not-for profit } \\
\text { Non-partisan } \\
\text { Non-violent } \\
\text { Shared } \\
\text { objectives } \\
\text { Political, social, } \\
\text { cultural, } \\
\text { economic } \\
\text { groups } \\
\text { Promote the }\end{array}$ & $\begin{array}{l}\text { Non-government } \\
\text { Non-profit } \\
\text { Self-constituting } \\
\text { Voluntary } \\
\text { associations }\end{array}$ & $\begin{array}{l}\text { Non-government } \\
\text { Non-profit / no } \\
\text { commercial } \\
\text { interests } \\
\text { Faith-based } \\
\text { associations } \\
\text { Alternative legal } \\
\text { status } \\
\text { No single } \\
\text { definition } \\
\text { Public interest / } \\
\text { public wellbeing }\end{array}$ & $\begin{array}{l}\text { Non- } \\
\text { government } \\
\text { Not for profit } \\
\text { Have } \\
\text { commercial } \\
\text { interests } \\
\text { Sectoral } \\
\text { wellbeing } \\
\text { Lobbying }\end{array}$ \\
\hline
\end{tabular}




\begin{tabular}{|c|c|c|c|c|}
\hline $\begin{array}{l}\text { How they } \\
\text { can be } \\
\text { identified } \\
\text { by their } \\
\text { mission }\end{array}$ & $\begin{array}{l}\text { Public good } \\
\text { orientation }\end{array}$ & Specific cause & $\begin{array}{l}\text { Adding value to } \\
\text { research practices } \\
\text { Being responsible } \\
\text { in research }\end{array}$ & $\begin{array}{l}\text { Promote a } \\
\text { sector }\end{array}$ \\
\hline $\begin{array}{l}\text { Legal } \\
\text { status }\end{array}$ & Legal status i & ly to be relevant bu & ficult for us to deter & hine \\
\hline $\begin{array}{l}\text { Areas of } \\
\text { interest }\end{array}$ & $\begin{array}{l}\text { Promotion of } \\
\text { public } \\
\text { engagement, } \\
\text { deliberative } \\
\text { democracy }\end{array}$ & $\begin{array}{l}\text { Benefits that CSOs } \\
\text { bring: } \\
\text { Capacity building } \\
\text { Enable citizen } \\
\text { participation } \\
\text { Increased } \\
\text { transparency } \\
\text { Mitigate effects of } \\
\text { business interests } \\
\text { Strengthen } \\
\text { representation }\end{array}$ & $\begin{array}{l}\text { Interested in } \\
\text { constraints, } \\
\text { activities, impact } \\
\text { and motivations of } \\
\text { CSOs in research }\end{array}$ & \\
\hline Action & Interested in & Research needs to & Interested in & Interested in \\
\hline
\end{tabular}




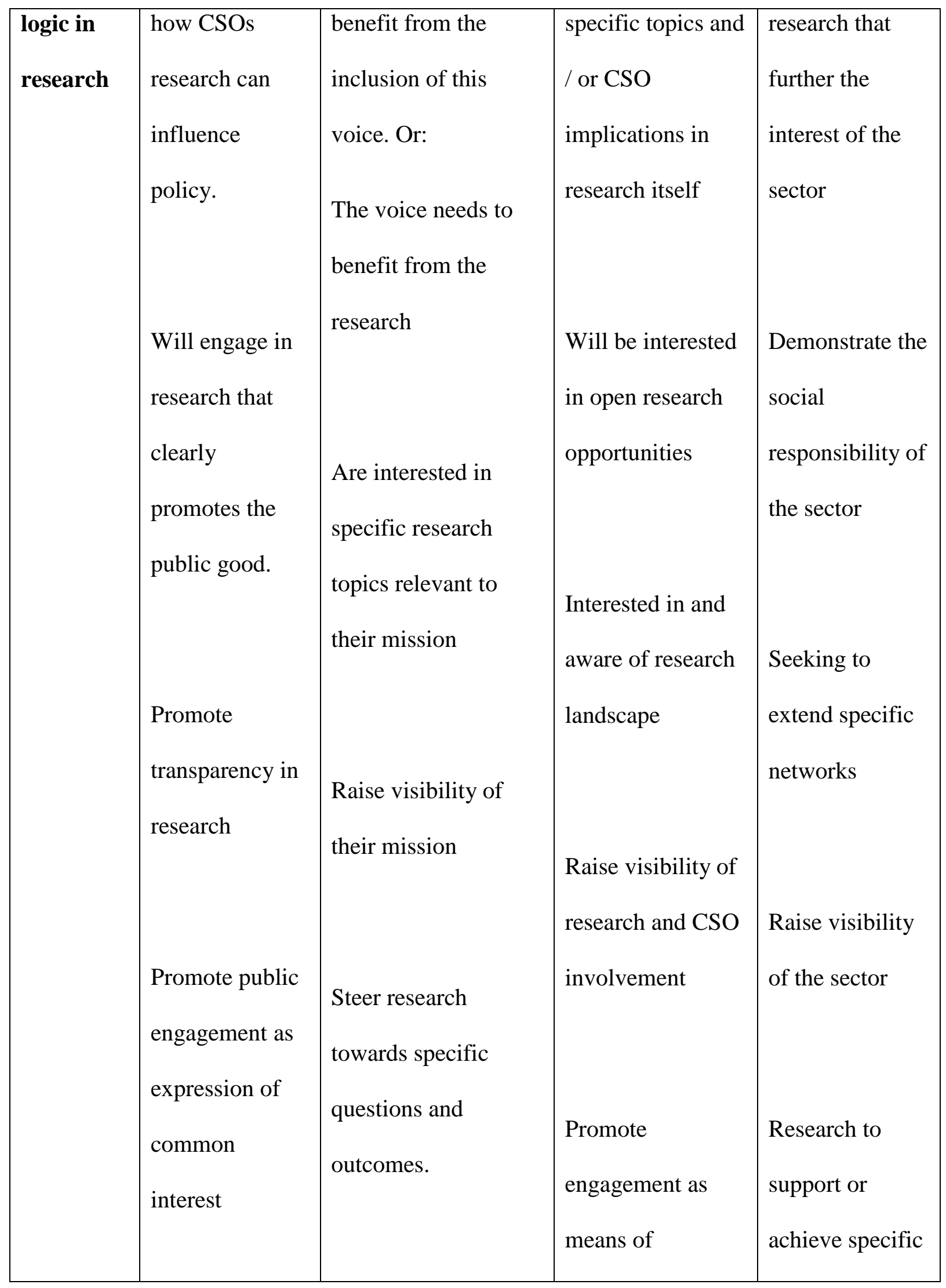




\begin{tabular}{|l|l|l|l|}
\hline & & improving & (policy) goals \\
& research, & increasing & \\
& & legitimacy of & \\
& findings. & \\
\hline
\end{tabular}

